\title{
Fluid Balance and Sodium Losses During Indoor Tennis Match Play
}

\author{
Matthew J.E. Lott and Stuart D.R. Galloway
}

\begin{abstract}
This study assessed fluid balance, sodium losses, and effort intensity during indoor tennis match play (17 \pm $2{ }^{\circ} \mathrm{C}, 42 \% \pm 9 \%$ relative humidity) over a mean match duration of $68.1 \pm 12.8 \mathrm{~min}$ in 16 male tennis players. Ad libitum fluid intake was recorded throughout the match. Sweat loss from change in nude body mass; sweat electrolyte content from patches applied to the forearm, calf, and thigh, and back of each player; and electrolyte balance derived from sweat, urine, and daily food-intake analysis were measured. Effort intensity was assessed from on-court heart rate compared with data obtained during a maximal treadmill test. Sweat rate $(M \pm S D)$ was $1.1 \pm 0.4 \mathrm{~L} / \mathrm{hr}$, and fluid-ingestion rate was $1.0 \pm 0.6 \mathrm{~L} / \mathrm{hr}$ (replacing $93 \% \pm 47 \%$ of fluid lost), resulting in only a small mean loss in body mass of $0.15 \% \pm 0.74 \%$. Large interindividual variabilities in sweat rate (range $0.3-2.0 \mathrm{~L} / \mathrm{hr}$ ) and fluid intake (range $0.31-2.52 \mathrm{~L} / \mathrm{hr}$ ) were noted. Whole-body sweat sodium concentration was $38 \pm 12 \mathrm{mmol} / \mathrm{L}$, and total sodium losses during match play were $1.1 \pm 0.4 \mathrm{~g}$ (range $0.5-1.8$ g). Daily sodium intake was $2.8 \pm 1.1 \mathrm{~g}$. Indoor match play largely consisted of low-intensity exercise below ventilatory threshold (mean match heart rate was $138 \pm 24$ beats $/ \mathrm{min}$ ). This study shows that in moderate indoor temperature conditions players ingest sufficient fluid to replace sweat losses. However, the wide range in data obtained highlights the need for individualized fluid-replacement guidance.
\end{abstract}

Keywords: hydration, exercise, environment

Fluid and electrolyte losses have been measured in many different sports such as football (Shirreffs, Sawka, \& Stone, 2006), American football (Godek, Bartolozzi, \& Godek, 2005), basketball (Osterberg, Sperber, Lacambra, Baker, \& Murray, 2005), and ice hockey (Palmer \& Spriet, 2008). Those studies showed that a mean voluntary dehydration of 1-3\% loss of body mass occurs when fluid is ingested ad libitum. However, in the context of tennis, players have more frequent scheduled breaks in play that provide substantially more opportunity to ingest fluids than is available in other sports. Researchers have assessed sweat rates, sweat electrolyte concentration, and fluid-intake strategies of tennis players outdoors in hot environments, including consecutive days of match play and in players with a tendency to suffer heat cramps (Bergeron, 1996, 2003; Bergeron, Armstrong, \& Maresh, 1995; Bergeron, Maresh, et al., 1995). Those tennis studies have typically shown a mean loss of $1-2 \%$ of body mass during periods of match play. These data indicate that increased opportunity for fluid ingestion does not reduce the voluntary dehydration incurred during tennis matches played outdoors under hot conditions.

Voluntary dehydration of 1-2\% of body mass is generally not considered detrimental to performance (Sawka et al., 2007), but there is considerable individual variability in the impact of hypohydration on endurance or skill performance. Baker, Dougherty, Chow, and Kenney

The authors are with the School of Sport, University of Stirling, Stirling, Scotland.
(2007) highlighted this variability in basketball players. A $2 \%$ loss of body mass led to significantly slower timed sprint drills and reduction in successful shot outcomes, but at $1 \%$ loss of body mass some individuals suffered declines in performance. Studies in tennis have observed that players often commence a match in a hypohydrated state (Bergeron, Waller, \& Marinik, 2006; Hornery, Farrow, Mujika, \& Young, 2007), and further voluntary dehydration during matches in the heat is likely. However, no study has addressed the fluid or electrolyte requirements of tennis players during indoor environmental conditions. Cool or moderate environmental conditions are prevalent during indoor play, but reduced solar heat gain alongside reduced ability to lose heat through convective cooling may affect fluid-intake recommendations. Singles tennis matches often last over $90 \mathrm{~min}$, and, although many tournaments are held in challenging environments, many matches are played indoors in moderate ambient temperature conditions. Because little is known about the fluid and electrolyte losses of tennis players under indoor conditions, we undertook an investigation of players' responses in these environmental conditions.

The main aims of the current study were to observe the fluid-intake strategies, fluid and sodium losses, and match-play intensities of elite tennis players in an indoor environment. We hypothesized that the sweat rates and body-mass deficits recorded would be lower than those reported in previous tennis-specific studies. If so, this would enable players to more readily maintain fluid balance, and thus an emphasis on fluid replacement may not be as necessary as for outdoor warm conditions. 


\section{Methods}

Sixteen male tennis players (age $21.5 \pm 4.4$ years, mass $75.5 \pm 8.6 \mathrm{~kg}$, height $179.5 \pm 6.9 \mathrm{~cm}$, peak oxygen consumption $\left[\mathrm{VO}_{2 \text { peak }}\right] 4.48 \pm 0.62 \mathrm{~L} / \mathrm{min}, M \pm S D$ ) were recruited from the University Scholarship Tennis Squad and the Club Performance Program. Fourteen of the players were currently, or had been in the previous year, nationally ranked between 15 and 750 in Great Britain and competed regularly in tournament play. The other 2 regularly competed in tournaments but were not currently nationally ranked. The players were asked to attend two main trials. The first was a graded running test to exhaustion on a treadmill, and the second was a best-of-three-sets singles tennis match conducted indoors at the university tennis center. The research project was approved by the university Ethics of Research Committee, and each participant provided written informed consent.

On the first visit the players completed a prescreening questionnaire. Age, height and mass, resting blood pressure, and heart rate were recorded. Players then undertook a graded maximal running test to exhaustion. This test was used to determine their $\mathrm{VO}_{2 \text { peak }}$ and their heart-rate response to graded intensities of exercise. The players' $\mathrm{VO}_{2}$, ventilation, and heart rate were measured continuously using an online gas-analysis system (Sensormedics Vmax 29, Holland), and a continuous incremental protocol was performed on a Marquette 2000 treadmill. The data from this test were used to set up three heart-rate-intensity zones for analysis of the subsequent on-court match (as used to monitor training by Seiler and Kjerland, 2006). This method provided three intensity zones from which it was then possible to calculate how long each player spent in a specific zone during his subsequent tennis match. Zone 1 was defined as low intensity, below the first ventilatory threshold; Zone 2 was moderate intensity, between the ventilatory threshold and the respiratory compensation point; and Zone 3 was high intensity, above the respiratory compensation point.

For the second trial players arrived at the tennis center in the morning after breakfast and having completed a food- and fluid-intake diary over the previous $48 \mathrm{hr}$. No dietary or lifestyle restrictions were placed on them. On arrival, each was asked to empty his bladder, and the urine volume and a sample were obtained before nude body mass was recorded. Players provided a fingertip capillary blood sample and were fitted with a heart-rate monitor (Polar S625×). Sweat patches (3M Tegaderm absorbent patches, area $10 \mathrm{~cm}^{2}$ ) were then applied to four sites on each player's body: the midpoint of the right thigh between the knee and hip, the middle of the widest point of the right calf, the inside of the right forearm midway between the elbow and wrist, and the middle of the lower back just above the waistline. The patch sites were chosen for minimal disruption of tennis movement yet represented some of the best sites for estimating whole-body sodium loss as identified in our previous work (Patterson, Galloway, \& Nimmo, 2000). All sites were shaved with a handheld plastic-handled razor, prepared by wiping with an alcohol wipe, washed with deionized water, and dried with a clean electrolyte- free gauze swab. Before the patches were applied the mass of each (and all its accompanying packaging) was recorded using a set of electronic scales (Camlab ACB 300 , accurate to $\pm 0.01 \mathrm{~g}$ ). After the patches were applied the mass of all the remaining packaging was recorded, enabling determination of the exact mass of the patch applied to the skin. This subsequently enabled determination of sweat volume collected into the patch.

The players completed a standard 5-min match warm-up, which included ground strokes, volleys, and serves. They then played a best-of-three-sets match against a competitively matched opponent. Opponents were matched as closely as possible according to their Lawn Tennis Association rating and national ranking. Players wore only shirts, shorts, socks, and shoes throughout the warm-up and match. They retrieved their own balls during the match. The heart-rate monitor was started at the beginning of the match, and data were stored at 5-s intervals.

The temperature and humidity of the tennis center were recorded on a digital barometer (Cranlea \& Co., Birmingham) throughout each match. The players were allowed to consume any fluid ad libitum. They were not permitted to consume any immediately before or immediately after the match. They were also not permitted to spit out any of the fluid in their drink bottles or use it to wet their hair or face. After every change of ends the mass of their drink bottles was recorded using a set of electronic scales (Ohaus CS-2000 Compact, recording to the nearest $1 \mathrm{~g}$ ) to calculate how much fluid had been consumed. The elapsed time at each change of ends was also noted. In addition, a sample of the beverage consumed on court was stored for later analysis of its electrolyte content.

On match completion players were immediately taken back to the laboratory, where a 3-min postmatch capillary blood sample was obtained. The sweat patches were removed using a pair of sterile forceps (a new pair for each patch) and were placed inside preweighed sterile plastic tubes before the final mass was recorded. The change in mass of the patch and the duration of its contact with the skin enabled an estimate of local sweat rate at the patch site to be obtained as previously reported by Patterson et al. (2000). The samples were centrifuged to extract the sweat from the patches. The sweat obtained from each patch was transferred into an Eppendorf tube for later analysis of sweat osmolality and electrolytes. After the patches were removed the players emptied their bladders and towel-dried themselves, and a final nude body mass was recorded for each.

\section{Osmolality and Electrolyte Analysis}

Urine and sweat osmolality were measured in duplicate using the freezing-point-depression technique (Roebling osmometer), and electrolytes (sodium, potassium, and chloride) were determined in duplicate using an ionselective-electrode method on an EML105 analyzer (Radiometer, Copenhagen). The ion-selective-electrode method had previously been validated in our laboratory against flame photometry. Total sodium loss was calculated by multiplying the sodium concentration of sweat and urine samples $(\mathrm{mmol} / \mathrm{L})$ by the molecular weight of 
sodium (22.99) and the total volume of sweat and urine produced (L), as previously reported by Palmer and Spriet (2008). Because the thigh site has been shown to be the most representative of whole-body sweat sodium concentration from whole-body wash-down in two previous studies (Baker, Stofan, Hamilton, \& Horswill, 2009; Patterson et al., 2000), this single site was used to calculate whole-body sweat sodium loss. Capillary blood samples obtained before and after the match were analyzed for glucose, lactate, and electrolytes also using the EML105 analyzer. Samples of the drinks consumed on court were analyzed on the EML105 for sodium, potassium, and chloride content. Dietary intake in the $48 \mathrm{hr}$ before the match was analyzed using Microdiet nutritional-analysis software (University of Salford, McCance and Widdowson's reference database) to estimate macronutrient and electrolyte (sodium, potassium, and chloride) intake.

\section{Estimation of Sweat Loss and Sweat Rate}

No account of respiratory water losses or changes resulting from substrate oxidation and substrate exchange when calculating sweat rate from change in nude body mass was made. This is in accordance with previous research by Maughan, Merson, Broad, and Shirreffs (2004) and Shirreffs et al. (2005). However, we are aware that not correcting for these factors may result in overestimation of sweat losses (Maughan, Shirreffs, \& Leiper, 2007). Using the equations highlighted by Maughan et al. (2007) we calculated that, based on the intensity of exercise (from heart-rate data) and estimated substrate oxidation, the duration of match play, and the environmental conditions, incorporating these corrections would amount to a $0.26-\mathrm{L}$ overestimate in our sweat-loss data $(0.22-\mathrm{L} / \mathrm{hr}$ sweat rate). Although correction such as this would be technically correct, the final difference is small and practically difficult for coaches to use in their assessments of fluid requirements.

\section{Statistical Analysis}

Pre- to postmatch comparisons of plasma glucose, lactate, sodium, potassium, and chloride concentration, as well as pre- and postmatch urine electrolytes and osmolality, were analyzed using paired $t$ tests. Individual sweat rate and sweat composition from the different skin sites were compared directly using paired $t$ tests. Linear-regression analysis was performed to investigate relationships between prematch urine osmolality and fluid intake, sweat rate and drinking rate, sweat loss and fluid intake, and local sweat rate and sweat sodium concentration. All statistical tests were undertaken using SPSS version 15.0. All data are reported as $M \pm S D$.

\section{Results}

Each match was played indoors on a hard-court surface under moderate ambient temperature conditions. The mean temperature and relative humidity during matches were $17 \pm 2{ }^{\circ} \mathrm{C}$ and $42 \% \pm 9 \%$, respectively. The mean match playing time was $68.1 \pm 12.8 \mathrm{~min}$ (range 52.5-92.8 $\min )$.

\section{Fluid Intake and Composition}

The mean fluid intake during the best-of-three-sets tennis match was $1.09 \pm 0.63 \mathrm{~L}$. This ranged from $0.36 \mathrm{~L}$ in a match lasting $60.25 \mathrm{~min}$ to $2.51 \mathrm{~L}$ in a match lasting 59.66 $\mathrm{min}$. The mean fluid intake was $0.96 \pm 0.62 \mathrm{~L} / \mathrm{hr}$ (range $0.31-2.52 \mathrm{~L} / \mathrm{hr}$; Figure 1A). Fifteen of the 16 players consumed water (tap or mineral water) during their matches. Analyzed water samples contained $4 \pm 1 \mathrm{mmol} / \mathrm{L}$ sodium, $0 \pm 0 \mathrm{mmol} / \mathrm{L}$ potassium, and $6 \pm 1 \mathrm{mmol} / \mathrm{L}$ chloride. One player consumed a commercial diluted orange-flavored

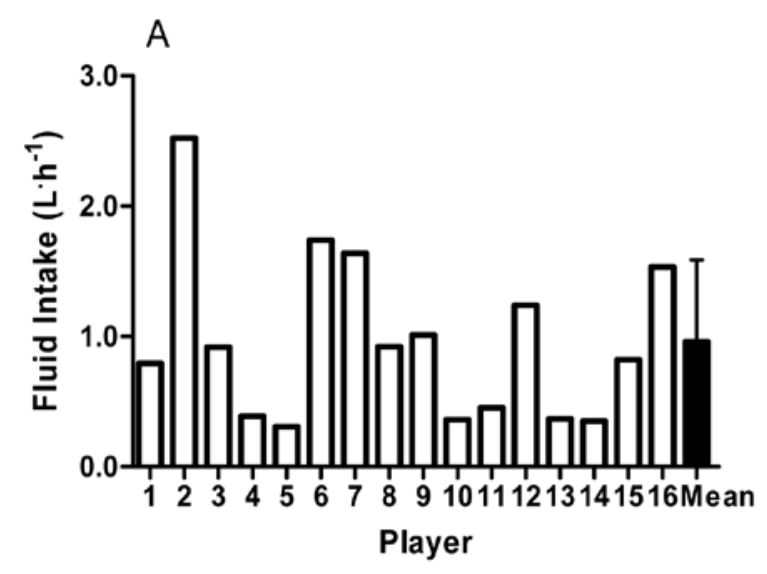

B
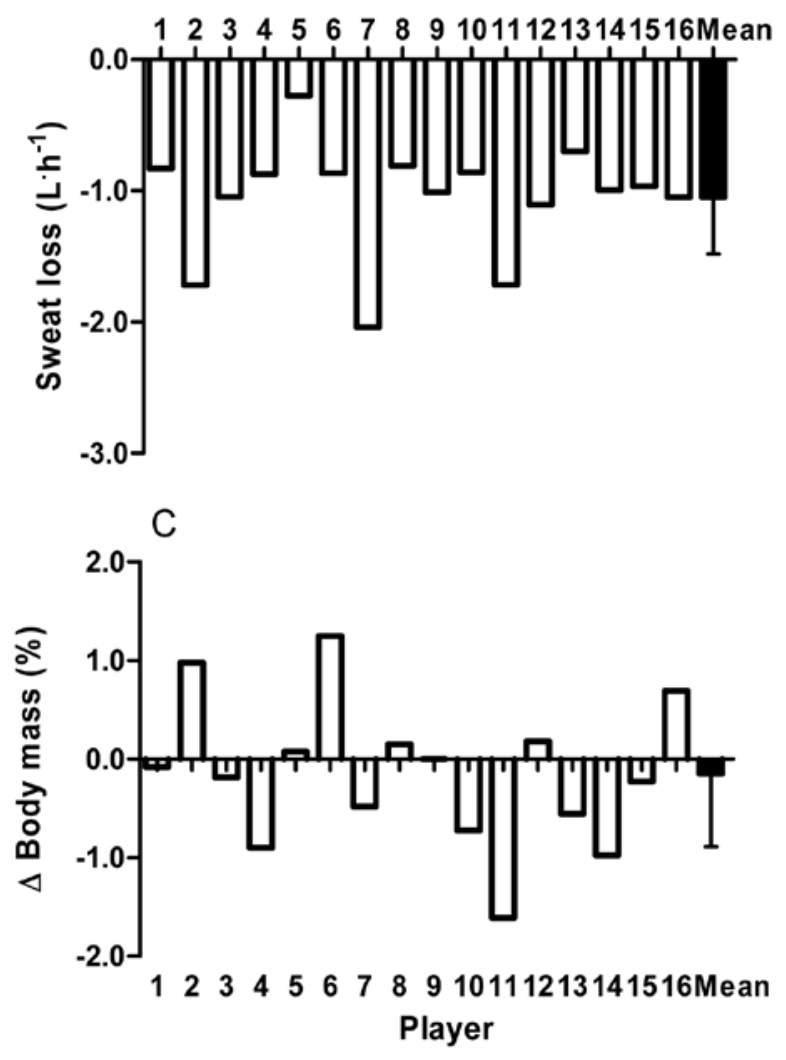

Figure 1 - Individual and $M \pm S D$ (A) fluid intake, (B) sweat loss, and (C) net fluid balance of 16 players during a best-ofthree-sets tennis match. 
drink. This drink contained $8 \mathrm{mmol} / \mathrm{L}$ sodium, $1.4 \mathrm{mmol} / \mathrm{L}$ potassium, and $14 \mathrm{mmol} / \mathrm{L}$ chloride.

Table 1 shows the mean fluid intake and mean percentage of total fluid intake at each change of ends during the matches, as well as the mean playing time at each change of ends. Players consumed the most fluid at the first change of ends, and the volume of fluid intake then declined progressively until the fifth change of ends, after which it remained relatively constant for the rest of the match.

\section{Fluid Loss, Sweat Rate, and Net Fluid Balance}

The estimated mean whole-body sweat loss during the match was $1.2 \pm 0.5 \mathrm{~L}$ (range $0.4-2.3 \mathrm{~L}$ ). The mean whole-body sweat rate was $1.1 \pm 0.4 \mathrm{~L} / \mathrm{hr}$ (range $0.3-2.0$ $\mathrm{L} / \mathrm{hr}$; Figure 1B). There was no significant difference in body mass pre- to postmatch $(75.5 \pm 8.6 \mathrm{~kg}$ pre, $75.4 \pm$ $8.6 \mathrm{~kg}$ post; $p>.05)$. There was a mean net body-fluid deficit of $0.1 \pm 0.6 \mathrm{~L}$ from pre- to postmatch. Body- mass change ranged from $1.6 \%$ loss to $1.3 \%$ gain, with a mean body-mass change of $-0.15 \% \pm 0.74 \%$ (Figure 1C). Thus, players on average ingested sufficient fluid to replace $93 \% \pm 47 \%$ of fluid losses from sweating, but this outcome was individually variable. One player replaced only $26 \%$ of his fluid losses, whereas another ingested over $200 \%$ of fluid lost.

\section{Sweat Electrolytes, Osmolality, and Local Sweat Rate}

Sweat electrolyte concentration, sweat osmolality, and local sweat rate at each of the four sampling sites are shown in Table 2. Sweat sodium and chloride concentration were significantly higher at the back site than at any other sampling sites $(p<.05)$. No significance was observed in sweat osmolality between sampling sites. The sweat rate from the back site was significantly greater than from the other three sites, and the sweat rate from the forearm was also significantly greater than that obtained from the calf site $(p<.05)$.

Table 1 Fluid Intake, Percentage of Total Fluid Intake, and Cumulative Playing Time at Each Change-of-Ends Break

\begin{tabular}{|c|c|c|c|}
\hline Changeover & Fluid intake (ml) & $\%$ of total fluid intake & Playing time (min) \\
\hline 1 & $171 \pm 127$ & $16 \pm 11$ & $2.57 \pm 1.08$ \\
\hline 2 & $114 \pm 78$ & $12 \pm 5$ & $8.38 \pm 3.02$ \\
\hline 3 & $111 \pm 77$ & $11 \pm 9$ & $15.47 \pm 4.35$ \\
\hline 4 & $101 \pm 82$ & $9 \pm 4$ & $23.03 \pm 5.43$ \\
\hline 5 & $88 \pm 86$ & $7 \pm 5$ & $30.35 \pm 6.21$ \\
\hline 6 & $130 \pm 120$ & $12 \pm 6$ & $36.09 \pm 6.36$ \\
\hline 7 & $81 \pm 83$ & $6 \pm 6$ & $42.04 \pm 6.53$ \\
\hline 8 & $87 \pm 47$ & $10 \pm 7$ & $50.43 \pm 7.13$ \\
\hline $9(n=13$ players $)$ & $103 \pm 74$ & $8 \pm 8$ & $56.55 \pm 7.51$ \\
\hline $10(n=10$ players $)$ & $85 \pm 62$ & $4 \pm 4$ & $62.36 \pm 7.01$ \\
\hline 11 ( $n=7$ players $)$ & $79 \pm 79$ & $3 \pm 4$ & $70.34 \pm 8.43$ \\
\hline $12(n=4$ players $)$ & $109 \pm 104$ & $3 \pm 5$ & $80.14 \pm 11.19$ \\
\hline
\end{tabular}

Note. Values are $M \pm S D$ for 16 players unless otherwise indicated.

Table 2 Sweat Electrolyte Concentration and Osmolality and Local Sweat Rate at Each of the Four Sweat-Sampling Sites

\begin{tabular}{lccccc}
\hline Site & $\mathbf{N a}^{+}(\mathbf{m m o l} / \mathbf{L})$ & $\mathbf{K}^{+}(\mathbf{m m o l} / \mathbf{L})$ & $\mathbf{C l}^{-}(\mathbf{m m o l} / \mathbf{L})$ & Osmolality $(\mathbf{m O s m o l} / \mathbf{k g})$ & Sweat rate $\left(\mathbf{m g}^{\prime} \mathbf{c m}^{-2} \cdot \mathbf{m i n}^{-1}\right)$ \\
\hline Forearm & $37 \pm 14$ & $4.9 \pm 2.0$ & $31 \pm 13$ & $111 \pm 21$ & $0.54 \pm 0.19 \dagger$ \\
Calf & $38 \pm 14$ & $5.0 \pm 2.0$ & $34 \pm 14$ & $118 \pm 26$ & $0.36 \pm 0.18$ \\
Thigh & $38 \pm 12$ & $4.5 \pm 2.0$ & $34 \pm 12$ & $112 \pm 13$ & $0.43 \pm 0.23$ \\
Back & $49 \pm 18^{*}$ & $4.5 \pm 1.0$ & $46 \pm 19 *$ & $125 \pm 13$ & $0.94 \pm 0.37 *$ \\
Mean & $41 \pm 15$ & $4.7 \pm 1.7$ & $36 \pm 15$ & $117 \pm 35$ & $0.57 \pm 0.19$ \\
Range & $23-79$ & $2.8-7.0$ & $19-74$ & $96-160$ & $0.28-0.94$ \\
\hline
\end{tabular}

Note Values are $M \pm S D$ for 16 subjects.

aSurface-area-weighted mean value from the four sampling sites.

$*$ Significant differences between back and all other sites $(p<.05)$. $\dagger$ Significant difference from calf site $(p<.05)$. 


\section{Urine Volume, Osmolality, and Electrolytes}

Urine volume was significantly higher postmatch (94 \pm $63 \mathrm{ml})$ than prematch $(44 \pm 32 \mathrm{ml})$. Urine electrolyte concentration and osmolality were not different from pre- to postmatch: urine sodium was $115 \pm 54 \mathrm{mmol} / \mathrm{L}$ prematch and $52 \pm 38 \mathrm{mmol} / \mathrm{L}$ postmatch; urine potassium was 49 $\pm 26 \mathrm{mmol} / \mathrm{L}$ prematch and $54 \pm 32 \mathrm{mmol} / \mathrm{L}$ postmatch; urine chloride was $139 \pm 74 \mathrm{mmol} / \mathrm{L}$ prematch and 107 $\pm 54 \mathrm{mmol} / \mathrm{L}$ postmatch; and urine osmolality was 788 $\pm 158 \mathrm{mOsmol} / \mathrm{kg}$ prematch and $695 \pm 207 \mathrm{mOsmol} / \mathrm{kg}$ postmatch.

In the current study 2 players had a preexercise urine osmolality above $900 \mathrm{mOsmol} / \mathrm{kg}$. Shirreffs and Maughan (1998) have previously shown this to reflect a $1.9 \%$ deficit in body mass. Seven more players in the current study had preexercise urine osmolality greater than $800 \mathrm{mOsmol} / \mathrm{kg}$. The range of urine osmolality was 366-1,099 mOsmol/kg.

\section{Dietary Analysis and Sodium Loss}

The mean energy intake (EI) over the 2 days of recording was $1,769 \pm 347 \mathrm{kcal} /$ day. The mean contributions to the player's diet were $223 \pm 39 \mathrm{~g} /$ day for carbohydrate $(47 \%$ of EI), $73 \pm 13 \mathrm{~g} /$ day for fat (37\% of EI), and $69 \pm 15 \mathrm{~g} /$ day $(16 \%$ of $\mathrm{EI})$ for protein.

The mean electrolyte loss (combined sweat and urine loss) observed during the match was estimated to be 1.1 $\pm 0.4 \mathrm{~g}$ for sodium. The mean daily dietary sodium intake was calculated to be $2.8 \pm 1.1 \mathrm{~g}$ (Figure 2).

\section{Match-Play Intensity, Blood Metabolites, and Plasma Electrolytes}

Heart rate on court ranged from 75 to 192 beats/min, indicating intensities in the range from rest to almost maximal intensity. The mean percentage of maximum heart rate sustained during the match was $71.4 \% \pm$ $6.11 \%$ (range $62.5-85.1 \%$ ), with a mean match heart rate of $138 \pm 23$ beats/min (Figure 3A). Players spent on average $74 \% \pm 18 \%$ of playing time in the low-intensity zone, $25 \% \pm 17 \%$ in the moderate-intensity zone, and $1 \% \pm 3 \%$ in the high-intensity zone (Figure 3B). The mean heart rate for the Zone 1-2 boundary was $141 \pm$ 12 beats/min and for the Zone 2-3 boundary was 184 \pm 8 beats/min.

Blood glucose concentration decreased and blood lactate concentration increased significantly $(p<.05)$ after the match compared with prematch values. Plasma sodium, potassium, and chloride concentration were not different between the prematch and postmatch samples (Table 3). Three players who ingested excess water in relation to sweat losses $(0.97 \% \pm 0.28 \%$ body-mass gain) showed a nonsignificant decline in plasma sodium concentration over the match period from $139 \pm 2$ to 137 $\pm 2 \mathrm{mmol} / \mathrm{L}$.
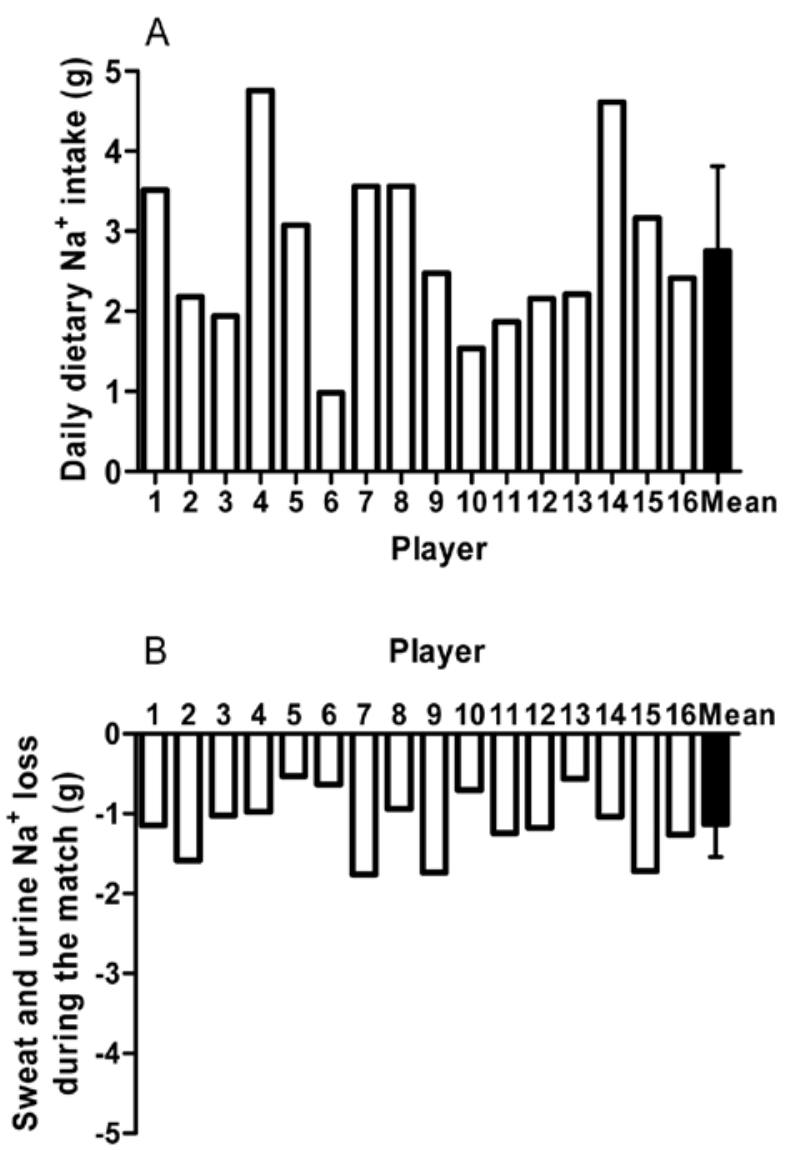

Figure 2 - Individual and $M \pm S D$ (A) estimated daily dietary sodium intake and (B) calculated whole-body sweat (from thigh site) and urine sodium loss of 16 tennis players during a singles best-of-three-sets tennis match.

\section{Relationship Between Hydration Status and Fluid Intake}

There was a significant relationship $(p<.05, r=.54)$ between whole-body sweat loss and total fluid intake during the matches. There was no relationship between sweat rate and drinking rate $(p>.05, r=.36$; Figure $4 \mathrm{~A})$, nor between total fluid intake and prematch urine osmolality $(p>.05, r=.03$; Figure 4B). There were no significant relationships between local sweat rate and sweat sodium concentration at each sweat-collection site.

\section{Discussion}

This study characterized the fluid balance and electrolyte losses of nationally ranked male tennis players during indoor match play. The key observations were that the players on average matched fluid consumption to sweat loss, and fluid ingestion throughout the match was individually variable. Urine osmolality indicated that some 

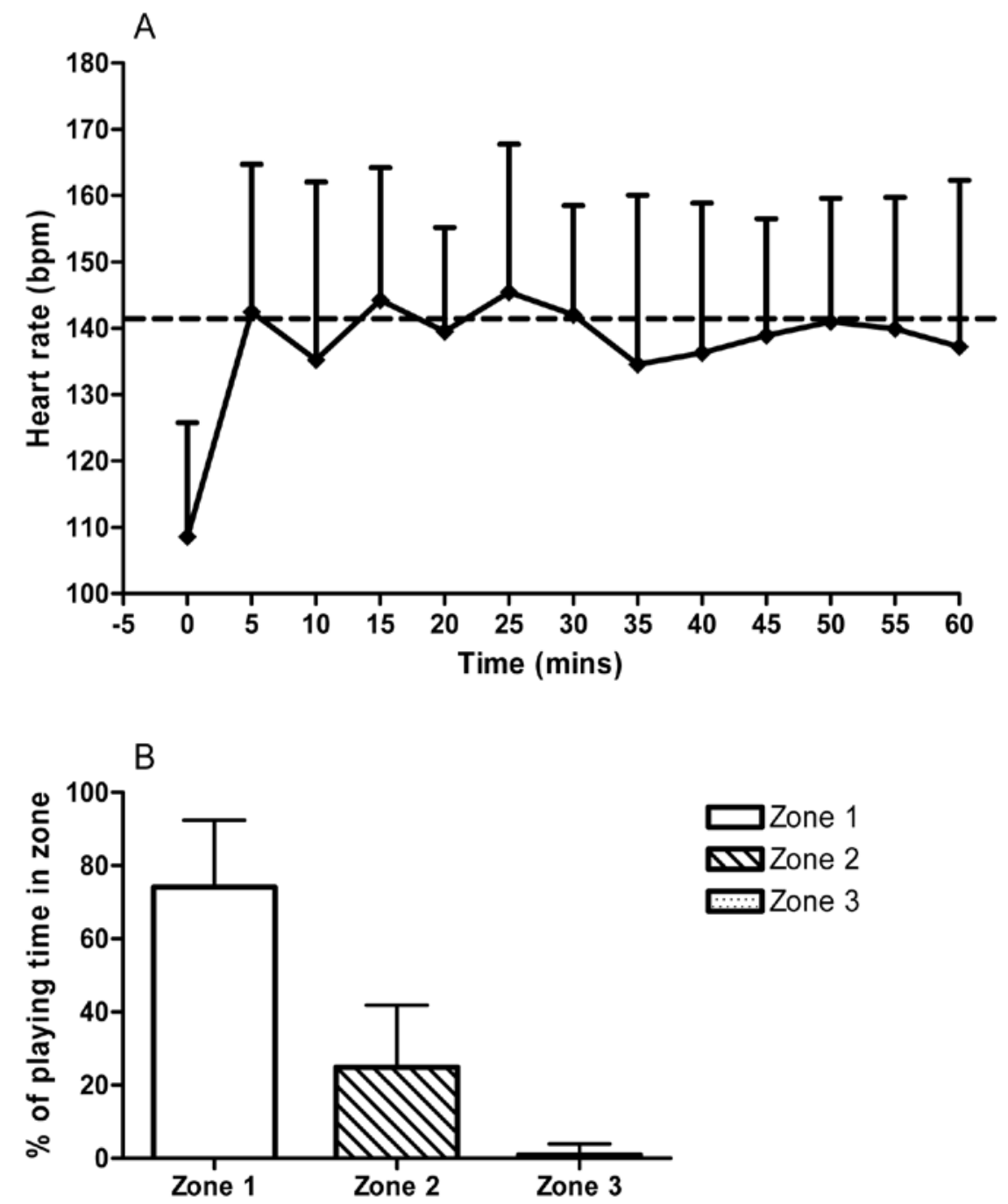

Figure 3 - (A) Heart rate sustained during the first $60 \mathrm{~min}$ of a best-of-three-sets tennis match and (B) percentage of time spent in low-intensity (Zone 1, mean HR $<141 \pm 12$ beats/min), moderate-intensity (Zone 2), and high-intensity (Zone 3, mean HR > 184 \pm 8 beats/min) activity, $M \pm S D$. The dotted line in the upper panel represents the heart rate corresponding to low intensity (Zone 1) identified from the laboratory treadmill testing session.

Table 3 Plasma Glucose, Lactate, Sodium, Potassium, and Chloride Concentrations (mmol/L) Recorded Pre- and Postmatch

\begin{tabular}{lcc}
\hline & Prematch & Postmatch \\
\hline Glucose & $6.16 \pm 1.04$ & $5.69 \pm 0.91^{*}$ \\
Lactate & $1.24 \pm 0.32$ & $2.03 \pm 1.08^{*}$ \\
$\mathrm{Na}^{+}$ & $139 \pm 1$ & $139 \pm 2$ \\
$\mathrm{~K}^{+}$ & $4.2 \pm 0.3$ & $4.1 \pm 0.7$ \\
$\mathrm{Cl}^{-}$ & $105 \pm 2$ & $105 \pm 3$ \\
\hline
\end{tabular}

Note. Values are $M \pm S D, N=16$.

*Significant difference from prematch value. players were moderately hypohydrated before match play. The intensity of match play was variable over a wide range; however, most time was spent in low-intensity activity, similar to outdoor tennis match-play intensity based on the heart-rate data reviewed by Fernandez, Mendez-Villanueva, and Pluim (2006).

Only a handful of studies have examined fluid balance and electrolyte losses in tennis players, and this is the first to examine these factors in an indoor environment, where the temperature did not exceed $20^{\circ} \mathrm{C}$ on any occasion. It is also the first to closely analyze players' on-court fluid-ingestion patterns. The ambient conditions in the current study were similar to those found in national indoor tournaments in the United Kingdom but 

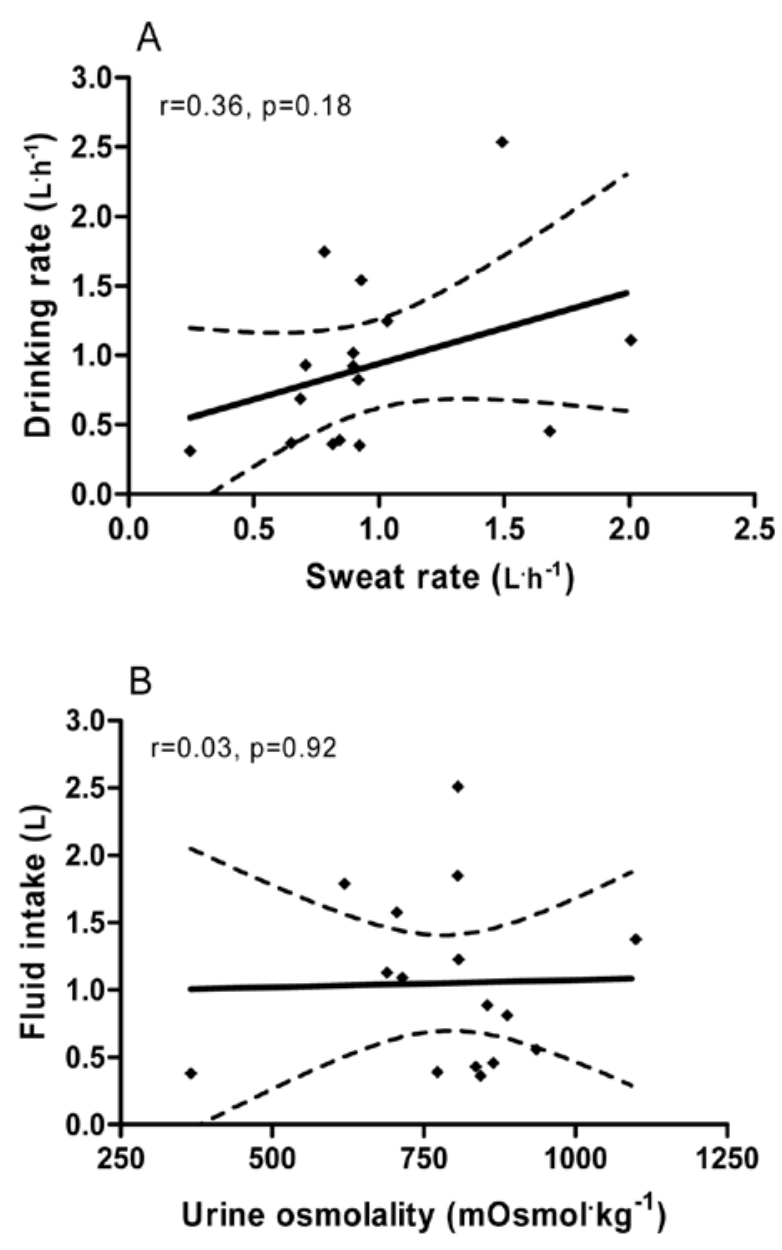

Figure 4 - Relationship (95\% confidence limits shown) between (A) sweat rate and on-court fluid-ingestion rate and (B) total fluid intake and preexercise urine osmolality during a tennis match. No significant relationship was observed $(p>.05)$.

less challenging than tournaments held overseas outdoors. The environment could be described as comfortable for the players involved.

\section{Hydration Status and Fluid Balance}

The sweat rate recorded $(1.1 \pm 0.4 \mathrm{~L} / \mathrm{hr})$ under the moderate ambient conditions $\left(17^{\circ} \mathrm{C}\right)$ of the current study was lower than that $(\sim 1.7 \mathrm{~L} / \mathrm{hr})$ reported for singles match play of men in a warm $\left(\sim 32^{\circ} \mathrm{C}\right)$ environment (Bergeron, Maresh, et al., 1995). Sweat rate was also lower than recorded during football training in hot conditions of 24-29 ${ }^{\circ} \mathrm{C}$ (Maughan et al., 2004) and $32 \pm 3{ }^{\circ} \mathrm{C}$ (Shirreffs et al., 2005) and those recorded during an intense practice session at $13.9^{\circ} \mathrm{C}$ in elite junior ice hockey players (Palmer \& Spriet, 2008). The lower sweat rate in the current study is consistent with the cooler ambi- ent conditions, the players' clothing restriction, and the match intensity. Furthermore, a lower sweat rate probably reflects reduced solar heat gain during play indoors.

On average, players replaced $93 \% \pm 47 \%$ of wholebody sweat loss. This is much more than reported by Elliot, Dawson, and Pyke (1985), in whose study the mean fluid intake across one 60-min singles match was $250 \mathrm{ml}$, representing only $26 \%$ of the total fluid loss. However, our results were similar to those of Hornery et al. (2007), whose players replaced $77 \%$ and $89 \%$ of total fluid loss during hard-court and clay-court singles matches. The current data suggest that because of the lower sweat rates and the frequent opportunities for fluid intake, the players in our study were able to replace a large proportion of sweat losses. Fluid intake at each change of ends, every 6-10 min, resulted in only a small mean loss of body mass during the match. However, the range of fluid intake among changes of ends was large, and in some cases this led to excessive fluid intake, with 3 players drinking more than $145 \%$ of their sweat losses (1 of whom exceeded $200 \%$ of sweat loss).

All other studies examining fluid loss in tennis players have reported a significant body-mass loss from pre- to postmatch. Elliot et al. (1985) reported an average fluid loss of $0.91 \mathrm{~kg}$ (1.3\% body mass) after one singles match outdoors at wet bulb globe temperature $21.5^{\circ} \mathrm{C}$, and Bergeron, Maresh, et al. (1995) reported a mean body-mass loss of $1.8 \%$ after two singles matches and one doubles match on the same day, but under more environmentally challenging conditions $\left(32.2 \pm 1.5^{\circ} \mathrm{C}\right)$. The cooler ambient temperature conditions in the current study enabled fluid intake to approach fluid loss. Skill and endurance performance are increasingly thought to be unaffected by dehydration until $2-3 \%$ of body mass is lost, and none of the players in the current study were close to that threshold.

Some players should be reminded to adhere to fluidintake guidelines (Sawka et al., 2007) and advised not to ingest too much electrolyte-free solution. There is potential danger in any sport from excessive water intake leading to hyponatremia (Noakes, Sharwood, Speedy, Hew, Reid, Dugas, Almond, Wharam, \& Weschler, 2005). In tennis players, Bergeron, Maresh, et al. (1995) demonstrated that when three matches were played on consecutive days, there was a trend for depletion in plasma sodium concentration, and this became significant on the fourth day. It is unclear what caused the change in plasma sodium concentration in their study because dietary intake exceeded measured electrolyte loss, but the likely cause is that players consumed only water during each match day. Excess water intake in relation to sweat loss in 3 players in the current study resulted in a nonsignificant decline in plasma sodium concentration of $2 \mathrm{mmol} / \mathrm{L}$ ( $139-137 \mathrm{mmol} / \mathrm{L})$ from pre- to postmatch. The magnitude of change within this range is not of immediate concern, but during several days of match play and longer matches, players such as these may require closer monitoring. 


\section{Sodium Loss}

The estimated mean whole-body sweat sodium concentration observed in this study by using the thigh sampling site alone $(38 \pm 12 \mathrm{mmol} / \mathrm{L})$ was similar to data from a range of other sports including professional football (30 $\pm 19 \mathrm{mmol} / \mathrm{L}$ and $49 \pm 12 \mathrm{mmol} / \mathrm{L}$; Maughan et al., 2004; Shirreffs et al., 2005). However, the sweat sodium concentration was higher than in tennis players who train and compete regularly in warmer environments, suggesting that players in the current study were not as heat acclimated as the American college players studied by Bergeron, Maresh, et al. (1995). Regular exposure to warmer environmental conditions results in reduced sweat sodium concentration for a given sweat volume, through increased reabsorptive ability of the eccrine sweat duct (Buono, Ball, \& Kolkhorst, 2007) without changing the positive relationship between sweat $[\mathrm{Na}]$ and local sweat rate. In the current study, no relationship was observed between sweat [Na] and local sweat rate at any of the sampling sites. This is likely because of the heterogeneity of acclimation status in our group of players or the differences in intensities of exercise sustained by individuals during matches.

Two players commenced their match hypohydrated according to urine osmolality (>900 mOsmol/kg; Shirreffs \& Maughan, 1998), and 7 others approached this threshold for hypohydration (with urine osmolality $>800$ $\mathrm{mOsmol} / \mathrm{kg}$ ). Similar findings have been reported before by Bergeron et al. (2006) and Hornery et al. (2007), showing that tennis players tended to commence match play in a hypohydrated state. Maughan et al. (2004) reported that some footballers were mildly hypohydrated, and 1 severely $(1,254 \mathrm{mOsmol} / \mathrm{kg})$, before a 90 -min training session. Palmer and Spriet (2008) have shown that a group of 44 junior ice hockey players were largely on the verge of hypohydration before an intense 1-hr practice session. Hornery et al. (2007) suggest that technical elements of the service action could be affected by adverse physiological conditions including hypohydration, so achieving euhydration before a match may be recommended. In the current study, despite some players' commencing exercise in a hypohydrated state, they did not subsequently consume more fluid during the match than the other players. No relationship was observed between preexercise urine osmolality and fluid intake during the match.

In conclusion, the range of values for fluid intake, sweat loss, and electrolyte losses observed in this study demonstrates the large variability between individuals. Consequently, it is difficult to make a general conclusion on guidelines for fluid and electrolyte intake for teams or groups of players. However, the current data do provide support for the notion that individualized advice is vital (Maughan et al., 2004; Maughan \& Shirreffs, 2008; Palmer \& Spriet, 2008). We have observed that in moderate ambient indoor temperature conditions players on average do not lose as much sweat as in outdoor warmer environments and therefore tend to ingest sufficient fluid to replace their sweat losses. Contrary to reports in foot- ballers, runners, and some other sports, this indicates that fluid replacement is easier to achieve during indoor tennis match play because of the environment, the intensity of play sustained, and the regular breaks in play.

\section{References}

Baker, L.B., Dougherty, K.A., Chow, M., \& Kenney, W.L. (2007). Progressive dehydration causes a progressive decline in basketball skill performance. Medicine and Science in Sports and Exercise, 39(7), 1114-1123.

Baker, L.B., Stofan, J.R., Hamilton, A.A., \& Horswill, C.A. (2009). Comparison of regional patch collection vs. whole body washdown for measuring sweat sodium and potassium loss during exercise. Journal of Applied Physiology, 107, 887-895.

Bergeron, M.F. (1996). Heat cramps during tennis: A case report. International Journal of Sport Nutrition, 6, 62-68.

Bergeron, M.F. (2003). Heat cramps: Fluid and electrolyte challenges during tennis in the heat. Journal of Science and Medicine in Sport, 6(1), 19-27.

Bergeron, M.F., Armstrong, L.E., \& Maresh, C.M. (1995). Fluid and electrolyte losses during tennis in the heat. Clinics in Sports Medicine, 14, 23-32.

Bergeron, M.F., Maresh, C.M., Armstrong, L.E., Signorile, J.F., Castellani, J.W., Kenefick, R.W., . . Riebe, D.A. (1995). Fluid-electrolyte balance associated with tennis matchplay in a hot environment. International Journal of Sport Nutrition, 5, 180-193.

Bergeron, M.F., Waller, J.L., \& Marinik, E.L. (2006). Voluntary fluid intake and core temperature responses in adolescent tennis players: Sports beverage versus water. British Journal of Sports Medicine, 40, 406-410.

Buono, M.J., Ball, K.D., \& Kolkhorst, F.W. (2007). Sodium ion concentration vs. sweat rate relationship in humans. Journal of Applied Physiology, 103, 990-994.

Elliot, B., Dawson, B., \& Pyke, F. (1985). The energetics of singles tennis. Journal of Human Movement Studies, 11, 11-20.

Fernandez, J., Mendez-Villanueva, A., \& Pluim, B.M. (2006). Intensity of tennis match play. British Journal of Sports Medicine, 40, 387-391.

Godek, S.F., Bartolozzi, A.R., \& Godek, J.J. (2005). Sweat rate and fluid turnover in American football players compared with runners in a hot and humid environment. British Journal of Sports Medicine, 39(4), 205-211.

Hornery, D.J., Farrow, D., Mujika, I., \& Young, W. (2007). An integrated physiological and performance profile of professional tennis. British Journal of Sports Medicine, 41(8), 531-536.

Maughan, R.J., Merson, S.J., Broad, N.P., \& Shirreffs, S.M. (2004). Fluid and electrolyte intake and loss in elite soccer players during training. International Journal of Sport Nutrition and Exercise Metabolism, 14, 333-346.

Maughan, R.J., \& Shirreffs, S.M. (2008). Development of individual hydration strategies for athletes. International Journal of Sport Nutrition and Exercise Metabolism, 18, 457-472. 
Maughan, R.J., Shirreffs, S.M., \& Leiper, J.B. (2007). Errors in the estimation of hydration status from changes in body mass. Journal of Sports Sciences, 25(7), 797-804.

Noakes, T.D., Sharwood, K., Speedy, D., Hew, T., Reid, S., Dugas, J., . . . Weschler, L. (2005). Three independent biological mechanisms cause exercise-associated hyponatremia: Evidence from 2,135 weighed competitive athletic performances. Proceedings of the National Academy of Science, 102(51), 18550-18555.

Osterberg, K.L., Sperber, T.E., Lacambra, M., Baker, L.B., \& Murray, R. (2005). Fluid balance, hydration status, and sweat electrolyte concentrations in NBA basketball players during summer league games. Journal of Sports Sciences, 40, S39.

Palmer, M.S., \& Spriet, L.L. (2008). Sweat rate, salt loss, and fluid intake during an intense on-ice practice in elite Canadian male junior hockey players. Applied Physiology, Nutrition, and Metabolism, 33, 263-271.

Patterson, M.J., Galloway, S.D.R., \& Nimmo, M.A. (2000). Variations in regional sweat composition in normal human males. Experimental Physiology, 85, 869-875.
Sawka, M.N., Burke, L.M., Eichner, E.R., Maughan, R.J., Montain, S.J., \& Stachenfeld, N.S. (2007). American College of Sports Medicine position stand: Exercise and fluid replacement. Medicine and Science in Sports and Exercise, 39(2), 377-390.

Seiler, K.S., \& Kjerland, G.Ø. (2006). Quantifying training intensity distribution in elite endurance athletes: Is there evidence for an optimal distribution? Scandinavian Journal of Medicine \& Science in Sports, 16, 49-56.

Shirreffs, S.M., Aragon-Vargas, L.F., Chamorro, M., Maughan, R.J., Serratosa, L., \& Zachwieja, J.J. (2005). The sweating response of elite professional soccer players to training in the heat. International Journal of Sports Medicine, 26, 90-95.

Shirreffs, S.M., \& Maughan, R.J. (1998). Urine osmolality and conductivity as indices of hydration status in athletes in the heat. Medicine and Science in Sports and Exercise, 30(11), 1598-1602.

Shirreffs, S.M., Sawka, M.N., \& Stone, M. (2006). Water and electrolyte needs for football training and match play. Journal of Sports Sciences, 24(7), 699-707. 